\title{
Troncos de árvores monumentais como indicadores de degradação florestal no sul do Brasil
}

\author{
Monumental tree trunks as indicators of forest degradation in southern Brazil
}

\author{
Marcelo Callegari Scipioni ${ }^{\mathrm{I}}$
}

\begin{abstract}
Resumo
As maiores árvores foram as primeiras a serem extraídas das florestas. Desta forma, há poucos registros dos tamanhos dos indivíduos arbóreos de grande porte, o que gera desconhecimento sobre muitas espécies ameaçadas de extinção. O objetivo desta nota técnica foi mensurar os monumentos históricos de troncos de Araucaria angustifolia e Ocotea porosa e comparar com a situação atual dos remanescentes florestais. Monumentos de troncos acima de $2 \mathrm{~m}$ de diâmetro foram amostrados em ambas as espécies. Os monumentos foram visitados in loco, foram obtidos os registros biométricos de perímetro do tronco por meio de amostragem preferencial. Esses foram comparados com árvores vivas catalogadas nos inventários florestais estaduais, ressaltam a perda de grandes árvores e destacam a degradação ambiental pela ausência delas. Tais monumentos de grandes árvores serviram como indicadores ambientais e são um patrimônio natural que deve ser preservado e estudado pela ciência, assim como as últimas grandes árvores na Mata Atlântica. Novas políticas públicas de catalogação de árvores de grande porte devem ser priorizadas. É também necessário que a classificação de tamanho das maiores árvores seja disponibilizada para a sociedade, visando à preservação ambiental, estudos científicos, manejo e turismo de natureza.
\end{abstract}

Palavras-chave: Araucaria angustifolia; Ocotea porosa; Árvores gigantes; Grandes árvores antigas

\begin{abstract}
The largest-size trees were the first ones to be extracted from forests. There are few records of the size of individual large trees for many species threatened with extinction. The objective of this technical note was to measure the monumental-size trunks of Araucaria angustifolia and Ocotea porosa and compare them with the current size of their populations in forest remnants. Trunk sizes over $2 \mathrm{~m}$ in diameter were sampled for both species. The monuments were visited on site, when photographic and biometric records of trunk perimeter were obtained by preferential sampling. Comparison with the now standing trees cataloged in the state forest inventories demonstrates the loss of large-size trees and highlights the environmental degradation. Presence of monumental-size trees in the Atlantic Forest thus may serve as an environmental indicator. Monumental-size trees represent a natural heritage that must be preserved and scientifically studied. Public policies for cataloging large-size trees should be prioritized. Classification of the largest trees by size must be made available to the society to further environmental preservation, scientific studies, management and nature tourism.
\end{abstract}

Keywords: Araucaria angustifolia; Ocotea porosa; Giant tree; Large old trees

I Engenheiro Florestal, Dr., Professor do Departamento de Agricultura, Biodiversiade e Florestas, Centro de Ciências Rurais, Universidade Federal de Santa Catarina, Rod. Ulysses Gaboardi Km 03, CEP 89520-000, Curitibanos (SC), Brasil. marcelo.scipioni@gmail.com (ORCID: 0000-0002-09235661) 


\section{Introdução}

Existem muitas espécies arbóreas com diferentes tamanhos, idades e formas. Algumas espécies apresentam formas de copas com aspectos estéticos únicos; um exemplo clássico é o pinheiro-brasileiro (Araucaria angustifolia (Bertol.) Kuntze dominando o dossel da Floresta Ombrófila Mista no Sul do Brasil. Outras árvores são gigantescas e se destacam pelo porte, como acumuladoras de grande quantidade de biomassa, a exemplo de Sequoiadendron giganteum (Lindl.) J. Buchholz, considerada a maior árvore em volume no mundo. $\mathrm{O}$ ambiente em que crescem influencia no seu porte. As maiores árvores estão em ambientes úmidos tropicais e temperados (VAN PELT, 2001; TNG et al., 2012; CARDIM, 2018). Em ambientes secos, o crescimento é lento. Contudo, há registros de árvores milenares de pequeno porte, destacando-se a Pinus longeva $\mathrm{D}$. K. Bailey, considerada a espécie arbórea mais velha, com mais de 4 mil anos de idade (FERGUSON, 1979; LINDENMAYER; LAURANCE, 2016).

Essa variedade de árvores monumentais são alguns exemplos de elementos fundamentais que ligam os seres humanos à natureza. Muitos estudos a respeito de árvores monumentais destacam as árvores vivas maduras (LINDENMAYER; LAURANCE; FRANKLIN, 2012; VAN PELT, 2001) e não realçam os vestígios das árvores mortas (AMIGOS DE LOS ARBOLES VIEJOS, 2015; CARDIM, 2018). Algumas situações, por exemplo, o desmatamento, reduziram significativamente o histórico de vida de certas espécies de grande porte e de alto valor econômico. A perda das grandes árvores é um fenômeno global (LINDENMAYER; LAURENCE, 2016). Atualmente, sobraram poucos vestígios das florestas originais na Mata Atlântica, principalmente da estrutura de porte de espécies arbóreas importantes (CARDIM, 2018). No Sul do Brasil, espécies importantes, como a araucária, recentemente estão sendo catalogadas (SCIPIONI et al., 2018). O cenário demonstra ampla perda de exemplares de grande porte, restando pouquíssimos indivíduos vivos quando comparados com as árvores amostradas nos inventários florestais governamentais (SCIPIONI et al, 2019).

As estruturas lenhosas das árvores apresentam variadas características químicas e físicas que influenciam nos diferentes níveis de conservação da sua madeira. Espécies arbóreas com extrativos químicos na madeira são menos suscetíveis ao ataque de cupins e outros insetos xilófagos. Registros de madeira, a exemplo de Sequoiadendron giganteum (Lindl.) J. Buchholz, podem ser observados em Sierra Nevada, na Califórnia, sem nenhum tratamento para preserválos. Essas árvores são atrações em parques nacionais americanos, nos quais, além de árvores vivas, os restos de troncos caídos e cepas cortadas há mais de um século estão visíveis para os mais de dois milhões de visitantes ao ano (STRONG, 2000).

O pinheiro-brasileiro, o jequitibá (Cariniana legalis (Mart.) Kuntze), a canafístula (Peltophorum dubium (Spreng.) Taub.) e a imbuia (Ocotea porosa (Nees \& Mart.) Barroso) são alguns exemplos dessas grandes árvores nativas com potencial de conservação e uso para educação ambiental, dendrocronologia, conservação da história e uso turístico em unidades de conservação como parques ou ambientes urbanos. Entre essas espécies estão a imbuia (Ocotea porosa Barroso (Nees \& Mart.)) e o pinheiro-brasileiro (Araucaria angustifolia (Bertol.) Kuntze), que desempenharam papel fundamental no desenvolvimento econômico e na identidade cultural da região Sul do Brasil. Árvores gigantes mortas dessas espécies foram conservadas como monumentos por meio dos seus troncos. Esses monumentos estão expostos em áreas públicas como troféus dos ciclos madeireiros, demonstrando o grande porte raramente visto nas florestas remanescentes. Apesar da existência de instrumentos legais que impedem a exploração dessas espécies e o reconhecimento de espécies ameaçadas de extinção, a madeira dessas árvores até hoje é explorada pela indústria madeireira e por proprietários rurais (AMATO, 2008; CARVALHO, 2003; FARJON; FILER, 2013; SANTOS et al., 2015; THOMAS, 2013; VARTY; GUADAGNIN, 1998), em muitas situações de forma ilegal.

O resgate do conhecimento dendrométrico de árvores ameaçadas de extinção e seus materiais lenhosos são importante para conhecer o porte, desenvolver estudos de crescimento e dendrocronologia, e o uso turístico de espécies arbóreas vivas e estruturas mortas, como troncos ou discos de madeira. Assim, a presente nota técnica visa registrar as espécies arbóreas gigantes mortas de Araucaria angustifolia e Ocotea porosa preservadas como monumentos no Sul do Brasil e comparar os seus dados dendrométricos com dados dos inventários florestais recentes dos estados de Santa Catarina e do Rio Grande do Sul, além de servir como registro para coletas futuras de materiais lenhosos para estudos de dendrocronologia. 


\section{Material e métodos}

\section{Área de estudo}

A identificação de monumentos de árvores se concentrou nos estados de Santa Catarina, Rio Grande do Sul e Paraná. Espécies madeireiras mais importantes em ciclos extrativistas como imbuia e araucária direcionaram as pesquisas para a localização de monumentos. Essas espécies do estudo são Araucaria angustifolia e Ocotea porosa, ambas são características da Floresta Ombrófila Mista (Floresta com Araucária), também são encontradas em áreas de tensão ecológica na Floresta Estacional e Floresta Ombrófila Densa (Floresta Atlântica) (CARVALHO, 2003). A província de Missiones, na Argentina, foi incluída nesse estudo devido à proximidade regional e ao histórico de preservação de monumentos com troncos de árvores no parque temático La Aripuca, Puerto Iguazú - Argentina (Figura 1).

\section{Coleta de Dados}

A pesquisa foi conduzida durante mais de quatro anos, sendo que o trabalho de campo exigiu mais de $8.800 \mathrm{~km}$ em viagens entre estradas principais e secundárias. Primeiramente, realizou-se um levantamento teórico, fazendo buscas em literaturas históricas e técnicas (SCIPIONI et al., 2019; CARVALHO, 2003; MATTOS, 2011; INOUE et al., 1984; REITZ et al., 1978). Após, a pesquisa foi direcionada por meio de pesquisas em plataformas de buscas on-line. As palavras-chave utilizadas na pesquisa on-line foram "Araucária monumental", "Imbuia monumental", "tronco de árvore monumental", "tronco monumento" e "árvore morta". O contato de redes pessoais com acadêmicos, profissionais, pesquisadores e docentes também serviu de fonte de informação para localização dos monumentos (Tabela 1). A pesquisa das árvores monumentais foi contemplada em conjunto com a pesquisa de árvores vivas de araucária durante a realização do projeto Árvores Gigantes no Sul do Brasil (https://www.arvoresgigantes.org/) (SCIPIONI et al., 2019). Por fim, os monumentos foram visitados in loco, quando foram obtidos os registros fotográficos e biométricos de perímetro do tronco por meio de amostragem preferencial. A amostragem preferencial é aceita em ecologia quando se objetiva estudar ou confirmar padrões percebidos subjetivamente homogêneos. O método não considera importante a forma de seleção de unidades amostrais (PILLAR, 2007), principalmente neste estudo, com objetos bem definidos em situação de raridade e distribuição espacial em ambientes específicos.

\section{Figura 1 - Localização de troncos monumentais de Ocotea porosa e Araucaria angustifolia, conforme denominação numérica na Tabela 1. Mapa adaptado do IBGE (2012).}

Figure 1 - Location of the monumental-size trunks of Ocotea porosa and Araucaria, according to numerical denomination in Table 1. Map adapted from IBGE (2012).

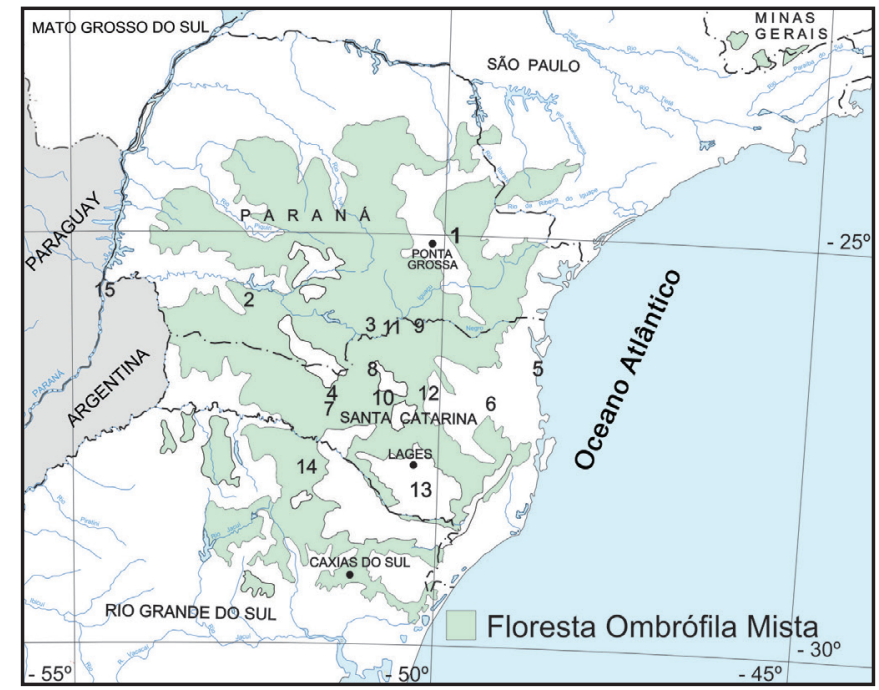

Fonte: Autor (2019) 
Tabela 1 - Lista dos monumentos amostrados na pesquisa de campo.

Table 1 - List of monumenal-size trees sampled in the field survey.

\begin{tabular}{|c|c|c|c|}
\hline Local & Espécies & Monumentos & $\begin{array}{c}\text { Coordenadas } \\
\text { Geográficas }\end{array}$ \\
\hline 1 Castro - PR, Brasil & $\begin{array}{c}\text { Araucaria } \\
\text { angustifolia }\end{array}$ & Tronco completo & $\begin{array}{l}24^{\circ} 44^{\prime} 20.40^{\prime \prime} \mathrm{S} \\
49^{\circ} 55^{\prime} 36.52 \text { "O }\end{array}$ \\
\hline 2 Coronel Vivida - PR, Brasil & Ocotea porosa & Duas bases e parte de troncos & $\begin{array}{c}25^{\circ} 59^{\prime} 1.56 ” \mathrm{~S} \\
52^{\circ} 33^{\prime} 59.11 \text { "O }\end{array}$ \\
\hline 3 União da Vitória - PR, Brasil & Ocotea porosa & Base de tronco, canoa & $\begin{array}{c}26^{\circ} 4^{\prime} 27.25^{\prime \prime} \mathrm{S} \\
51^{\circ} 9^{\prime} 45.64^{\prime \prime O}\end{array}$ \\
\hline 4 Água Doce - SC, Brasil & Ocotea porosa & Base de tronco & $\begin{array}{l}26^{\circ} 59^{\prime} 54.58^{\prime \prime} \mathrm{S} \\
51^{\circ} 33^{\prime} 12.72 \text { "O }\end{array}$ \\
\hline 5 Barra Velha - SC, Brasil & Ocotea porosa & Base de tronco & $\begin{array}{l}26^{\circ} 41^{\prime} 17.78^{\prime \prime} \mathrm{S} \\
48^{\circ} 41^{\prime} 43.98^{\prime \prime O}\end{array}$ \\
\hline 6 Brusque - SC, Brasil & Ocotea porosa & Base de tronco & $\begin{array}{c}27^{\circ} 5 ’ 37.77 ” \mathrm{~S} \\
48^{\circ} 55 ’ 17.93 ” \mathrm{O}\end{array}$ \\
\hline 7 Catanduvas - SC, Brasil & Ocotea porosa & Base de tronco & $\begin{array}{c}27^{\circ} 6 \text { ' } 10.20 " \mathrm{~S} \\
51^{\circ} 38^{\prime} 44.14 \text { "O }\end{array}$ \\
\hline 8 Caçador - SC, Brasil & Ocotea porosa & Base de tronco & $\begin{array}{c}26^{\circ} 47^{\prime} 24.79 ” \mathrm{~S} \\
51^{\circ} 00^{\prime} 4.18^{\prime \prime} \mathrm{O}\end{array}$ \\
\hline 8 Caçador - SC, Brasil & Ocotea porosa & Base de tronco & $\begin{array}{c}26^{\circ} 46^{\prime} 51.24^{\prime \prime} \mathrm{S} \\
51^{\circ} 1 \text { '1.09”O }\end{array}$ \\
\hline 9 Canoinhas - SC, Brasil & Ocotea porosa & Base de tronco & $\begin{array}{l}26^{\circ} 11^{\prime} 21.00^{\prime \prime} \mathrm{S} \\
50^{\circ} 22^{\prime} 34.50 " \mathrm{O}\end{array}$ \\
\hline 10 Fraiburgo - SC, Brasil & $\begin{array}{c}\text { Araucaria } \\
\text { angustifolia e } \\
\text { Ocotea porosa }\end{array}$ & Base de tronco, disco de madeira & $\begin{array}{c}27^{\circ} 1 \text { '2.99”S } \\
50^{\circ} 55^{\prime} 39.16 ” O\end{array}$ \\
\hline 11 Porto União - SC, Brasil & Ocotea porosa & Base de tronco & $\begin{array}{c}26^{\circ} 15^{\prime} 23.28^{\prime \prime} \mathrm{S} \\
51^{\circ} 4^{\prime} 4.85^{\prime \prime} \mathrm{O}\end{array}$ \\
\hline 11 Porto União - SC, Brasil & Ocotea porosa & Base de tronco & $\begin{array}{l}26^{\circ} 16^{\prime} 32.28 ” \mathrm{~S} \\
51^{\circ} 3 ’ 13.80^{\prime \prime} \mathrm{O}\end{array}$ \\
\hline 12 Santa Cecília - SC, Brasil & Ocotea porosa & Base de tronco & $\begin{array}{l}26^{\circ} 57^{\prime} 25.73^{\prime \prime} \mathrm{S} \\
50^{\circ} 25^{\prime} 12.88^{\prime \prime O}\end{array}$ \\
\hline 13 São Joaquim - SC, Brasil & $\begin{array}{c}\text { Araucaria } \\
\text { angustifolia }\end{array}$ & Base de tronco & $\begin{array}{l}28^{\circ} 17^{\prime} 40.71^{\prime \prime} \mathrm{S} \\
49^{\circ} 55^{\prime} 58.74 \text { "O }\end{array}$ \\
\hline 14 Tapejara - RS, Brasil & $\begin{array}{c}\text { Araucaria } \\
\text { angustifolia }\end{array}$ & Base de tronco & $\begin{array}{c}28^{\circ} 4^{\prime} 0.51^{\prime \prime} \mathrm{S} \\
52^{\circ} 1^{\prime} 24.79^{\prime \prime} \mathrm{O}\end{array}$ \\
\hline $\begin{array}{l}15 \text { Puerto Iguazú, Misiones, } \\
\text { Argentina }\end{array}$ & $\begin{array}{l}\text { Araucaria } \\
\text { angustifolia }\end{array}$ & Tronco completo & $\begin{array}{l}25^{\circ} 37^{\prime} 7.21^{\prime \prime} \mathrm{S} \\
54^{\circ} 33^{\prime} 30.63^{\prime \prime O}\end{array}$ \\
\hline
\end{tabular}

Fonte: Autor (2019)

\section{Informações dendrométricas}

Os monumentos de árvores mortas foram considerados estruturas de tronco em 
que é possível identificar a espécie e obter informações dendrométricas. As medições dos troncos ocorreram de fevereiro de 2017 a outubro de 2018. O critério de seleção para troncos monumentais foi um diâmetro a altura do peito (DAP) maior ou igual a $150 \mathrm{~cm}$, definido para as árvores gigantes de Araucaria angustifolia (SCIPIONI et al., 2019). O perímetro de tronco dos monumentos foi medido a altura do peito com fitas métricas. Registros dendrométricos disponíveis nos monumentos também foram considerados (O. porosa - 5; Araucaria angustifolia 14). O único monumento que teve seu volume estimado devido à preservação completa do tronco foi uma araucária localizada na Fazenda Capão Alto, em Castro - PR.

Informações biométricas, diâmetro e altura das espécies foram comparadas com a bibliografia (MATTOS, 2011; INOUE et al., 1984; REITZ et al., 1978) e os dados dos inventários florestais dos estados de Santa Catarina e Rio Grande do Sul (VIBRANS et al., 2013; RIO GRANDE DO SUL, 2018). A Argentina não tem inventário florestal em escala estadual. Uma descrição completa dos projetos e protocolos de amostragem dos inventários florestais pode ser encontrada nos sites IFCRS - Inventário Florestal Contínuo do Rio Grande do Sul (http://coralx.ufsm.br/ifcrs/) e IFFSC - Inventário Florestal Florístico de Santa Catarina (http://www.iff.sc.gov.br/). Gráficos de dispersão de diâmetro e altura das árvores vivas dos inventários florestais, em conjunto com os dados dos diâmetros dos troncos das árvores mortas (monumentos), foram utilizados para representar os tamanhos das espécies arbóreas, Araucaria angustifolia e Ocotea porosa. Nos monumentos utilizou-se o valor de três metros de altura, no gráfico de dispersão diâmetro x altura, com o objetivo de padronizar a comparação diamétrica com as árvores vivas.

\section{Resultados e discussão}

As árvores monumentais representam uma pequena porcentagem em uma população, ocupando a parte superior da faixa etária. No entanto, raramente há informações demográficas suficientes para fazer uma comparação confiável entre o tamanho e a idade de uma determinada árvore e o restante da população da mesma espécie. Além disso, como resultado de cortes feitos para diferentes propósitos, os indivíduos de referências muitas vezes carecem de árvores que puderam envelhecer naturalmente. Isso dificulta o conhecimento do porte, o cálculo da média de longevidade e a expectativa de vida. No entanto, muitas vezes é possível reconhecer árvores que claramente sobreviveram mais tempo do que a maioria dos indivíduos da espécie em questão (AMIGOS DE LOS ARBOLES VIEJOS, 2015) ou caso desse trabalho, por meio de registro de troncos. Nesse trabalho foram possíveis reconhecer os portes extremos das imbuias e a araucárias por meio dos monumentos de lenho.

\section{Monumentos de Ocotea porosa}

A imbuia é uma árvore muito apreciada devido a sua importância histórica na economia regional de Santa Catarina. É a árvore símbolo do estado desde 1973 (SANTA CATARINA, 2017), mas não há reconhecimento das árvores monumentais no estado. Foi a espécie madeireira de maior valor econômico na região de sua distribuição geográfica (PR, SC e RS). Contudo, a es pécie está a meaçada de extinção, sendo vulnerável em Santa Catarina e em perigo no Rio Grande do Sul (VARTY; GUADAGNIN, 1998; CNCFlora, 2019). Não existem indivíduos de grande porte com diâmetros superiores aos $2 \mathrm{~m}$ nos inventários florestais estaduais (VIBRANS et al., 2013), oposto aos troncos monumentos. Esses monumentos são encontrados no litoral e planalto, em sua maioria troncos de grandes árvores expostos principalmente em praças e portais de entradas de cidades (Figura 2). 
Figura 2 - Monumentos de Ocotea porosa: (a) Sítio Casaburi, União da Vitória - PR; (b) Praça Vereador Rodolfo Nickel, Caçador - SC; (c) Posto Madeira, Caçador - SC; (d) Praça João Macagnan, Água Doce - SC; (e) Portal Turístico, Canoinhas - SC; (f) Portal Turístico, Porto União - SC; (g) Parque Zoobotânico, Brusque - SC; (h) Parada Ferreti, Rodovia BR 101, Barra Velha - SC; (i) Vila Ondini, Coronel Vivida - PR; (j) Armazém da Madeira - BR 282, Catanduvas - SC; (k) Indústria de painéis de madeira Bonet, Santa Cecília - SC; (l) Floresta René Frey, Fraiburgo - SC.

Figure 2 - Monumental-size trunks of Ocotea porosa: (a) Sítio Casaburi, União da Vitória; (b) Praça Vereador Rodolfo Nickel, Caçador, SC; (c) Posto Madeira, Caçador, SC; (d) Praça João Macagnan, Água Doce, SC; (e) Portal Turístico, Canoinhas, SC; (f) Portal Turístico, Porto União, SC; (g) Parque Zoobotânico, Brusque, SC; (h) Parada Ferreti, BR 101 Highway, Barra Velha, SC; (i) Vila Ondini, Coronel Vivida, PR; (k) Wood Industry Bonet, Santa Cecília, SC; (j) Armazém da Madeira - BR 282, Catanduvas, SC; (l) Floresta René Frey, Fraiburgo, SC.

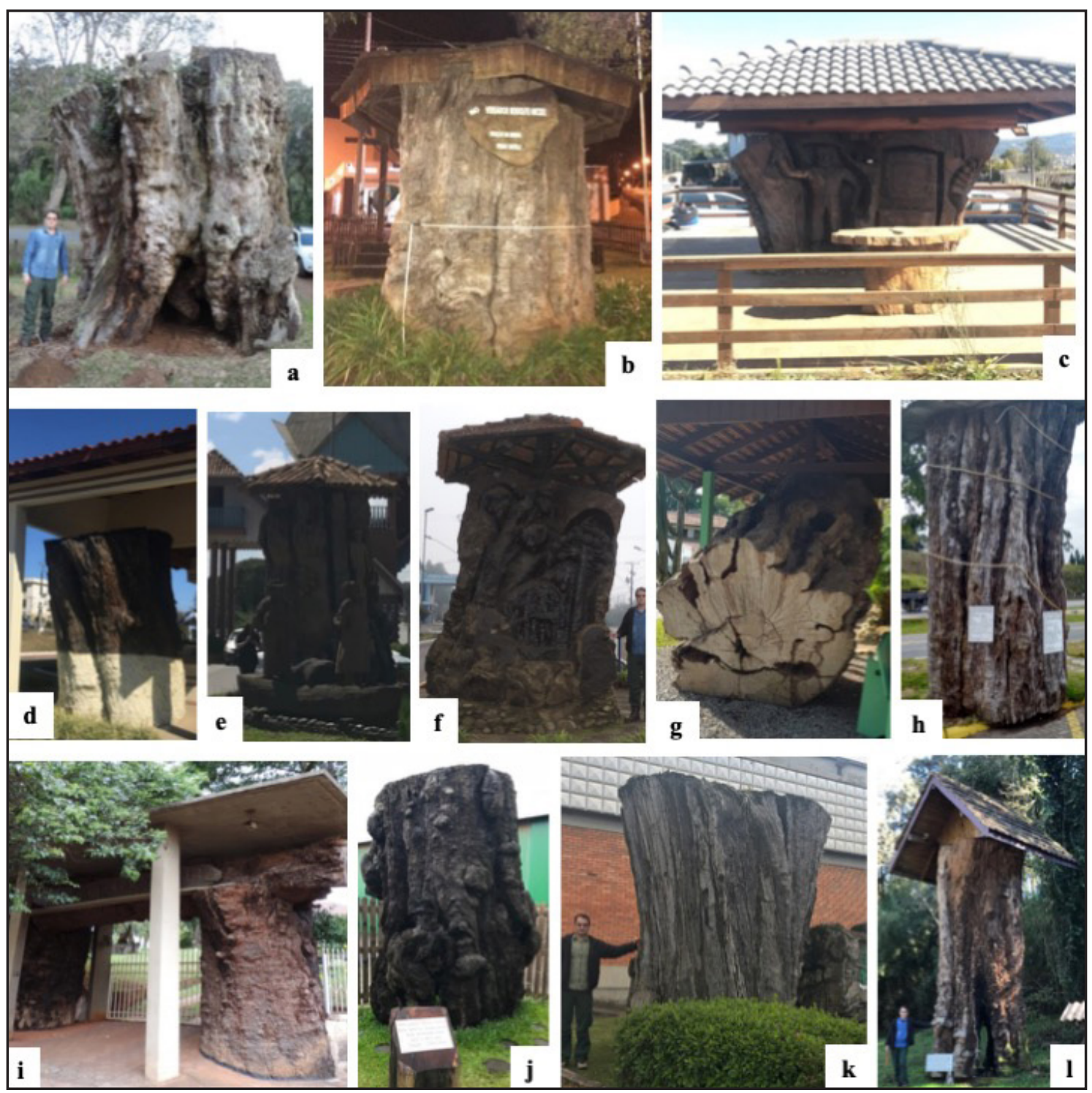

Fonte: Autor (2019) 
O maior tronco foi encontrado no portal da cidade de Canoinhas - SC tendo o perímetro de 8,83 m (DAP: 2,81 m). Apenas um exemplar de tronco foi registrado em área rural, no município de União da Vitória - PR, com perímetro de 8,39 m (DAP: 2,67 m) (Figura 2a). Na cidade de Caçador SC, dois grandes monumentos foram encontrados. O tronco bruto de 7,42 $\mathrm{m}$ de perímetro (DAP: $2,36 \mathrm{~m}$ ) em uma pequena praça (Figura $2 \mathrm{~b}$ ) e um tronco esculpido por Joacir Barzotto em março de 2007, localizado anexo ao posto Madeira entre a Avenida Comendador Selvino Caramore e a Rodovia Honorino Moro (Figura 2c). O tronco bifurcado apresentou 6,79 m de perímetro (DAP: $2,16 \mathrm{~m})$ a altura do peito.

No ano de 2012, o município de Água Doce - SC revitalizou a praça João Macagnan, em que um tronco de imbuia de 6,65 m (DAP: 2,11 m) foi disposto sobre uma cobertura em conjunto com uma locomotiva a vapor destacando a história do ciclo da madeira (Figura 2d). Troncos esculpidos de imbuia também são destaques na cidade de Porto União - SC, representando árvores do passado entre 1,5 a 2,0 m de diâmetro (Figura 2f). No munícipio de Barra Velha - SC, ao lado da BR-101, está um tronco com o perímetro de 6,84 m (DAP: 2,17 m) (Figura 2h). Na frente da empresa de painéis de madeira Bonet, em Santa Cecília - SC, dois troncos são expostos, respectivamente com perímetros de 6,43 m (DAP: 2,04 m) e 5,59 m (tronco na horizontal - DAP: $1,78 \mathrm{~m}$ ) (Figura 2k). Um tronco de 6,99 m (DAP: 2,22 m) está exposto ao lado da BR $282 \mathrm{em}$ Catanduvas - SC (Figura 2j).

No Parque Zoobotânico de Brusque - SC, existe um tronco de 5,97 m (DAP: 1,95 m) (Figura $2 \mathrm{~g})$. Esse cenário se repete em outros monumentos representados na Figura 2. O monumento de imbuia na Floresta René Frey, em Fraiburgo - SC, foi perdido no ano de 2017, mas sua imagem está registrada na Figura $2 k$. A perda total do monumento foi em razão de um incêndio provocado pelo culto de acender velas para a imagem de santo dentro da cavidade. Apesar do grande tamanho dos monumentos encontrados, a espécie teve o seu maior registro, de 3,26 m de diâmetro, em 1962, numa exposição regional em Três Barras - SC, conforme tronco registrado por Raulino Reitz no Projeto Madeira de Santa Catarina (REITZ et al., 1978). No Projeto Madeira do estado do Paraná, o registro para a espécie foi de $1,80 \mathrm{~m}$ de DAP no município de General Carneiro (INOUE et al., 1984).

\section{Monumentos de Araucaria angustifolia}

Araucária apresentou diferentes formas de monumentos preservados, como disco, base de tronco e tronco completo. Entre eles, destacam-se troncos inteiros protegidos por grandes coberturas (Figura 3). O tronco existente na Fazenda Capão Alto - SC, em Castro, teve 28,15 $\mathrm{m}$ de comprimento e $6,06 \mathrm{~m}$ de perímetro sem casca na posição $1,3 \mathrm{~m}$ de altura (Figura 3f-h). O volume estimado foi $32,9 \mathrm{~m}^{3}$. Outro tronco completo está localizado no Parque La Aricupa, Misiones, Argentina (DAP: 1,85 m). Em uma representação de arapuca estruturada com troncos de diversas espécies, está um tronco de araucária com 27 metros de comprimento e 500 toneladas representando a estrutura de acionamento da armadilha (Figura 3d-e). No Parque René Frey, em Fraiburgo, existe um monumento em disco de madeira com mais de 200 anos expondo a cronologia dos anéis de crescimento com eventos históricos (Figura 3c). Esse monumento destaca o local com uma floresta original e árvores gigantes (SCIPIONI, 2018).

No município de Tapejara - RS é possível encontrar o maior monumento de base de tronco de araucária, com mais de 400 anos de idade, constituindo-se em um dos principais atrativos turísticos do município (Figura 3a). Antes de se tornar um monumento, o pinheiro vivo destacava-se em meio à paisagem com mais $25 \mathrm{~m}$ de altura e $6,75 \mathrm{~m}$ de circunferência (DAP: 2,14 m). Localizava-se na estrada de saída para Santa Cecília, a $1 \mathrm{~km}$ da sede do município. Parte da araucária foi derrubada em virtude dos fortes ventos em 2015, sobrando apenas o tronco, totalmente oco. Para preservar a história dessa árvore, o proprietário Orildo Bacega doou o pinheiro ao município, que o transformou no monumento denominado Arcângelo Pereira (in memoriam) no dia 22 de janeiro de 2016. O monumento está exposto no Parque Municipal Ângelo 
Eugênio Dametto (PREFEITURA DE TAPEJARA, 2018).

Figura 3 - Monumentos de Araucaria angustifolia: (a) Arcângelo Pereira, Tapejara - RS; (b) Manoel Joaquim Pinto, São Joaquim - SC; (c) Floresta René Frey, Fraiburgo - SC; (d - e) La Aripuca, Puerto Iguazú, Argentina; (f, g, h) Fazenda Capão Alto, Castro - PR.

Figure 3 - Monumental-size trunks of Araucaria angustifolia: a) Arcângelo Pereira, Tapejara, RS; (b) Manoel Joaquim Pinto, São Joaquim, SC; (c) Floresta René Frey, Fraiburgo, SC; (d - e) La Aripuca, Puerto Iguazú, Argentina; (f, g, h) Fazenda Capão Alto, Castro, PR state.

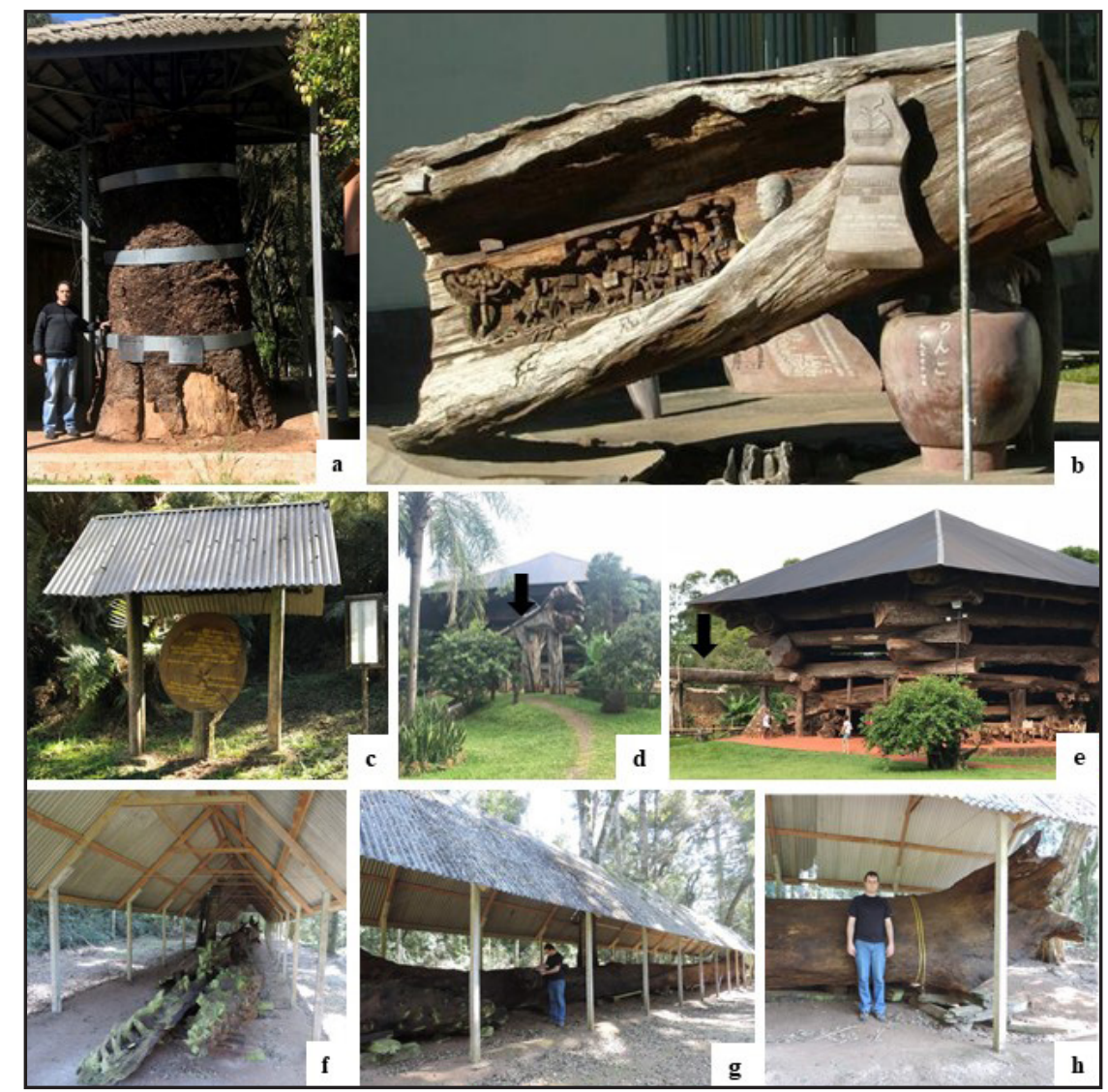

Fonte: Autor (2019)

Localizado ao lado da Prefeitura Municipal de São Joaquim - SC está o monumento Manoel Joaquim Pinto. Este conta a saga dos tropeiros que desbravaram a região (Figura 3b). O tronco inclinado (DAP: $1,50 \mathrm{~m}$ ) sugere o pinheiro derrubado e o fim do ciclo da madeira na floresta de araucária. A escora do tronco é uma maçã que representa um novo ciclo econômico para cidade iniciado a partir de 1969. Ao lado dessa maçã está fincado um pinhão, também esculpido em pedra, escorando o tronco. Desse pinhão vinga um broto, com os dizeres: "nova geração-esperança”, sugerindo o plantio do pinhão, cujo broto germinado simboliza a esperança com a chegada da nova geração, seja de plantas pelo reflorestamento, seja de novos cidadãos ao município. No tronco está esculpida uma tropa de animais, conduzida por bandeirantes paulistas, devidamente identificados pelas vestes próprias, como a aba do chapéu dobrada para cima, pelas bruacas típicas, presas nas mulas. Essa tropa toma a direção de cima para baixo no tronco, pois, geograficamente, São Paulo fica em latitude acima de Santa Catarina, e o seu deslocamento, na busca de novos horizontes, deu-se de norte para o sul (PREFEITURA DE SÃO JOAQUIM, 2018). 


\section{Comparações dendrométricas}

Os monumentos de araucária foram árvores que ultrapassavam 1,5 m de diâmetro. Elas são superiores a todas as árvores de araucárias mensuradas nos inventários estaduais de Santa Catarina (IFFSC) e do Rio Grande do Sul (IFCRS), representando um patrimônio natural que deve ser preservado para as gerações futuras. Os monumentos de Tapejara e Castro enquadram-se ao reduzido número de árvores com mais de $2 \mathrm{~m}$ de diâmetro; se estivessem vivas, seriam classificadas como araucárias gigantes (SCIPIONI et al., 2019), semelhantes às árvores gigantes vivas que apresentam grandes cavidades ao longo do tronco. Em comparação aos monumentos de imbuias, ambas as espécies apresentam semelhança em tamanho de base de tronco, no entanto as araucárias tiveram um número reduzido de monumentos de árvores mortas.

Nos dados dos inventários florestais estaduais de Santa Catarina e do Rio Grande do Sul, os tamanhos máximos registrados para árvores vivas de imbuias foram, respectivamente, 1,64 m e $0,36 \mathrm{~m}$ de diâmetro a altura do peito. Os tamanhos dessas árvores são inferiores aos troncos dos monumentos que representam as grandes árvores antes do início do ciclo de corte. Esse resultado é idêntico para as maiores araucárias registradas nos inventários florestais com diâmetros de $107 \mathrm{~cm}$ (SC) e $143 \mathrm{~cm}$ (RS). A ausência de árvores vivas de grande porte nos inventários florestais em classes de diâmetros $>2 \mathrm{~m}$ realçam a importância dos grandes monumentos como registros históricos do potencial dendrométrico dessas espécies (Figura 4). A falta de indivíduos arbóreos de grandes dimensões reflete o efeito preocupante da degradação ambiental das florestas no Sul do Brasil pela contínua exploração madeireira e falta de recrutamento de novos indivíduos em classes de diâmetros superiores. Destacando que os remanescentes florestais estão muito longe de apresentar populações maduras de ambas as espécies com árvores de grande porte (VIBRANS et al., 2013; SCIPIONI, 2018). Esses monumentos apresentam potencial de estudos científicos em dendrocronologia e manejo florestal.

\section{Novas políticas de proteção dos monumentos e das árvores gigantes}

As árvores monumentais são incomuns porque, por definição, representam apenas uma pequena porcentagem de uma população de árvores. Em todo o mundo, o valor da singularidade é reconhecido por si só. Isso é razão suficiente para os proprietários e agentes públicos, como seus atuais guardiões, assumirem o dever de proteger tais árvores para as gerações futuras. Essas árvores devem ser registradas e valorizadas como tal após sua morte, embora, paradoxalmente, algumas vezes árvores mortas não são consideradas como monumentos em certas espécies (AMIGOS DE LOS ARBOLES VIEJOS, 2015). Depois de morrer, algumas árvores mantêm muitos aspectos de valores vivos como sua importância cultural, histórica, longevidade e/ou tamanho que devem ser igualmente mantidos e preservados, independentemente da madeira viva ou morta, a exemplo da imbuia e araucária.

A araucária é a espécie símbolo do Sul do Brasil pela importância alimentícia, ampla distribuição geográfica e domínio visual na paisagem (FONSECA et al., 2009; SANTOS et al., 2002). Contudo, a imbuia foi mais representativa em monumentos devido a sua maior durabilidade da madeira, resistente ao ataque de fungos e insetos pelo seu lenho moderadamente pesado (AMATO, 2008), apresentando troncos de grande dimensão sem grandes cavidades. A imbuia se destaca com a necessidade de baixa manutenção dos monumentos contra umidade e xilófagos. Ao contrário dos troncos monumentos de araucárias gigantes na entrada do antigo Vale da Neve, em São Joaquim, expostos ao tempo que foram perdidos, restando atualmente apenas o registro de Mattos (2011). Esse cuidado deve ser considerado ao tronco do município de Tapejara, que visivelmente está em processo de decomposição em um ambiente não controlado.

As grandes árvores antigas são organismos críticos e importantes atributos em florestas, áreas agrícolas e ambientes urbanos no mundo todo. No entanto, são vulneráveis à destruição intencional ou acidental e estão em risco de rápida extinção temporária ou mesmo permanente (LINDENMAYER et al., 2012; 2013). As políticas existentes no Brasil estão falhando mesmo com a restrição do corte de espécies arbóreas ameaçadas de extinção (Figura 5). O aproveitamento de material lenhoso derrubado por ação da natureza para uso na propriedade rural ou comércio nem sempre tem sua origem e usos rastreados. Derrubadas de árvores por meio de simulação do desenraizamento causado por ação de 
ventos tornou-se uma prática comum como forma de remoção de árvores para expansão de áreas agrícolas e uso da madeira.

Figura 4 - Tamanho dos monumentos de Ocotea porosa (A) e Araucaria angustifolia (B) em comparação dendrométrica a árvores vivas registradas em inventários florestais estaduais.

Figure 4 - Size of monumental-size trunks of Ocotea porosa (A) and Araucaria angustifolia (B) in a dendrometric comparison with live trees recorded in state forest inventories.

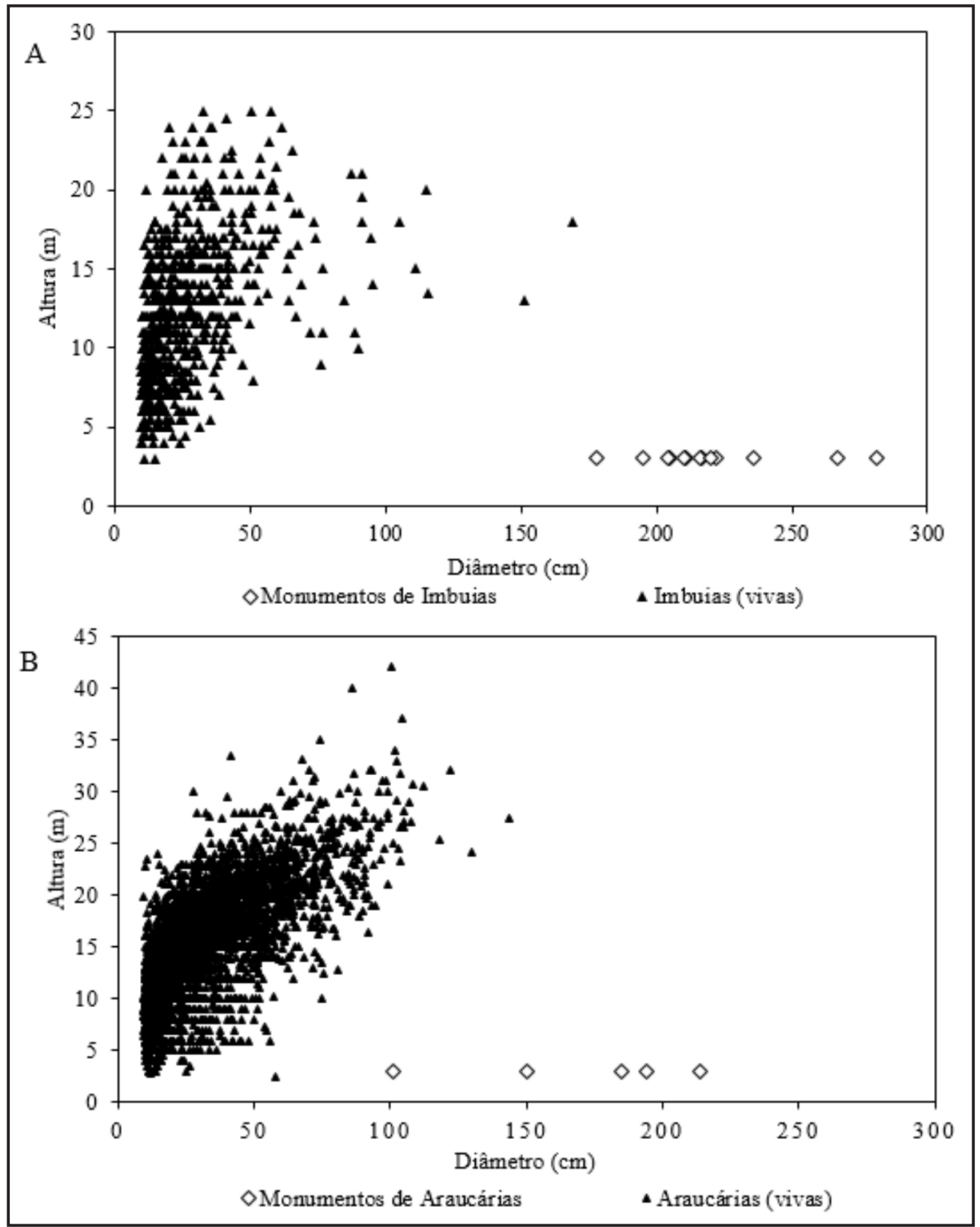

Fonte: Autor (2019)

No Código florestal brasileiro está previsto declarar qualquer árvore imune de corte, por motivo de sua localização, raridade, beleza ou condição de porta-sementes, cabendo isso ao poder público federal, estadual ou municipal (BRASIL, 2019). Em outros países, como a Argentina, a declaração de proteção de árvores está ao nível municipal e providencial. Entretanto, novas políticas e ações de gestão são necessárias para conservar as grandes árvores antigas existentes, primeiramente, a catalogação e o reconhecimento dos indivíduos, para em um segundo momento haver o recrutamento e a manutenção da estrutura etária das populações de árvores que assegure uma oferta perpétua de grandes árvores antigas, sustentando, assim, as propriedades funcionais ecológicas e econômicas que 
tais árvores fornecem em pé ou com o uso direto da madeira. Sem uma ação urgente, nesse cenário de degradação ambiental crescente, as funções bióticas, ecológicas e econômicas associadas às grandes árvores correm o risco de serem completamente perdidas (GUTIÉRREZ, 2016; LINDENMAYER et al., 2013; LUTZ et al., 2018; SCIPIONI, 2018; SCIPIONI et al., 2019). Lindenmayer et al. (2013) argumentam que as novas políticas e práticas são urgentemente necessárias para conservar as árvores grandes existentes no mundo, restaurando as populações ecologicamente eficazes e viáveis dessas árvores, gerenciando árvores e florestas em escalas temporais e espaciais muito mais longas do que as atualmente praticadas; bem como protegendo locais em que elas estão e os ambientes mais prováveis de seu desenvolvimento.

Figura 5 - Móveis de Araucaria angustifolia (a) e Ocotea porosa (b) de indivíduos centenários comercializados no Armazém da Madeira em Catanduvas - SC; árvore de Ocotea porosa (c), 2,74 m de DAP em Vargem Bonita - SC; $(\mathrm{d}$ - e) desmatamento de araucárias e imbuia gigante em Catanduvas - SC.

Figure 5 - Furniture made from trunks of centenarian individuals of Araucaria angustifolia (a) and Ocotea porosa (b) marketed at the Armazém da Madeira in Catanduvas, SC ; trunk of Ocotea porosa (c), $2.74 \mathrm{~m}$ of DHB in Vargem Bonita, SC; (d - e) logging of araucaria and giant imbuia trees in Catanduvas, SC state.

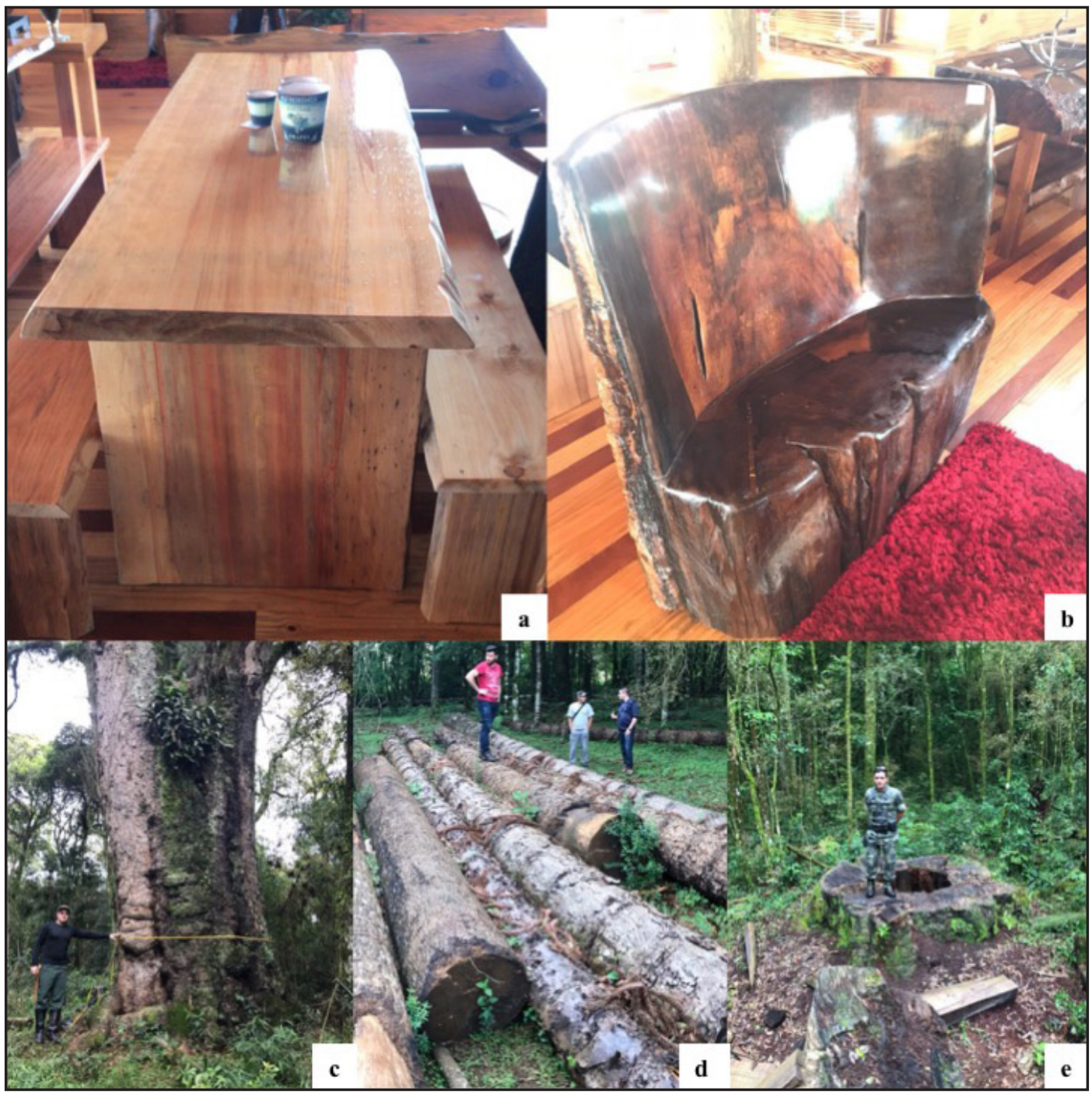

Fonte: Autor (2019) 
Políticas de mudanças no manejo florestal são fundamentais, incluindo cessação ou modificação da colheita de árvores gigantes e antigas, permitindo o uso da madeira somente de árvores caídas por ação da natureza (tempestades). Dentre as ações de conservação deve-se criar um planejamento para fomentar o recrutamento e manutenção de grandes árvores com a redução do desmatamento, redução das pressões de pastoreio e planejamento da urbanização (LINDENMAYER et al., 2013). Políticas de longo prazo para conservar e restaurar grandes e velhas árvores são contrárias em grande parte do manejo de recursos florestais existentes, em que a ação só ocorre quando uma "crise" se desenvolve, quando é tarde demais para evitar a "extinção temporária" das grandes árvores, destacando-se os poucos exemplos da imbuia e araucária gigantes. A definição do estágio de crescimento e modelagem demográfica, por exemplo, pode definir as políticas de longo prazo, ilustrando os impactos de longo prazo de fatores que levam a até mesmo modestos aumentos crônicos na mortalidade de grandes árvores antigas (LINDENMAYER et al., 2012) e a necessidade de estudos populacionais (SCIPIONI et al., 2019) e dendrocronológicos das últimas árvores gigantes, principalmente em espécies ameaçadas de extinção.

Existe a necessidade de um inventário específico para as grandes árvores, bem como um progresso nos instrumentos legislativos para definir e garantir a preservação das árvores de grande porte, tratando de forma individualizada cada árvore. Propõe-se que, para cada espécie arbórea nativa ou naturalizada, seja determinado um limite de tamanho de inclusão para classe monumental ou gigante. Para avançar na preservação dessas árvores vivas monumentais, propõe-se que a sociedade crie instrumentos para pagar pelos serviços ambientais, de assistência técnica para registro e conservação dos monumentos de árvores gigantes, além de incentivos fiscais como isenção de tributos territoriais aos particulares detentores dessas árvores de grande dimensão e incentivos ao desenvolvimento do turismo e à educação ambiental por meio do uso de árvores gigantes (SCIPIONI, 2018; SCIPIONI et al., 2019).

Os produtos madeireiros gerados de árvores monumentais devem ser móveis de valor agregado, identificados, certificados e rastreados para evitar o desmatamento e fortalecer o mercado legal de uso de peças de madeira de grandes dimensões, com publicidade e controle pelos órgãos consumidores e ambientais. A identidade e rastreabilidade dos produtos florestais de material lenhoso de grandes dimensões de espécies ameaçadas usadas em móveis de luxo por meio de registros da datação e tamanho dos anéis de crescimento é uma forma eficaz para a certificação de origem dos produtos. Assim, a dendrocronologia é uma ferramenta eficaz para esse tipo de controle e deve ser desenvolvida como política de Estado nos laboratórios de recursos florestais para dar suporte à cadeia de custódia dos produtos madeireiros de grande dimensão.

\section{Conclusões}

Os monumentos de troncos de madeira morta de araucárias e imbuias representam um patrimônio natural que deve ser preservado pela importância cultural, histórica, econômica e ambiental. Nessa nota técnica foram catalogados monumentos de grande dimensão que são superiores as árvores vivas de Ocotea porosa, que ressaltam a necessidade do recrutamento de árvores de grande porte para as gerações futuras. Observa-se uma lacuna sobre a longevidade dessas espécies que possibilita o uso de troncos mortos para pesquisas futuras de dendrocronologia. Novas políticas públicas de catalogação de madeira morta e árvores de grande porte devem ser priorizadas, visando ao conhecimento do ciclo de vida das árvores, ao turismo de natureza e ao controle da cadeia de custódia de material lenhoso e material para estudos científicos quando for derrubado por ação da natureza. 


\section{Agradecimentos}

O autor agradece aos professores Alexander C. Vibrans e Solon J. Longhi pelo acesso aos bancos de dados dos inventários florestais estaduais, além dos revisores pelos valiosos comentários para melhoria no texto.

\section{Referências}

AMATO, C. M. Ecologia de populações de Ocotea porosa (Nees) Barroso em áreas submetidas a diferentes graus de perturbação. 57 f. Dissertação (Mestrado em Ecologia e Conservação) Setor de Ciências Biológicas, Universidade Federal do Paraná, Curitiba, 2008.

AMIGOS DE LOS ARBOLES VIEJOS. Árboles Veteranos: guía avanzada para su gestión. Cheltenham: Pages Creative, 2015. 197 p.

BRASIL. Lei 12.651, de 25 de maio de 2012. Dispõe sobre a proteção da vegetação nativa. Disponível em: https://www.planalto.gov.br/ccivil_03/_ato2011-2014/2012/lei/112651.htm. Acesso em: 18 jul. 2019.

CARDIM, R. Remanescentes da Mata Atlântica: as grandes árvores da floresta original e seus vestígios. Editora Olhares: São Paulo, 2018. 340 p.

CARVALHO, P. E. R. Espécies Arbóreas Brasileiras. Brasília: Embrapa Informação Tecnológica, vol. 1, 2003. 1039 p.

FARJON, A.; FILER, D. An Atlas of the World's Conifers. Brill: Leiden e Boston, 2013. 512 p.

CNCFlora. Ocotea porosa in Lista Vermelha da flora brasileira versão 2012.2 Centro Nacional de Conservação de Flora. Disponível em: http://cncflora.jbrj.gov.br/portal/pt-br/profile/Ocotea\%20 porosa. Acesso em: 17 jul. 2019.

FERGUSON, C. W. Dendrochronology of Bristlecone Pine, Pinus longaeva. Environment International, Oxford, v. 2, p. 209-214, 1979.

FONSECA, C. R. et al. Floresta com Araucária: ecologia, conservação e desenvolvimento sustentável. Holos Editora, Ribeirão Preto, 2009. 328 p.

GUTIÉRREZ, Á. G. Árboles monumentales: un patrimonio natural no reconocido en Chile. Bosque, Valdivia, v. 37, p 445-449, 2016.

InOUE, M. T.; RODERJAN, C. V.; YOSHIKO, S. K. Projeto Madeira do Paraná. Curitiba, Fundação de Pesquisas Florestais do Paraná, 1984. 260 p.

LINDENMAYER, D. B.; LAURANCE, W. F. The ecology, distribution, conservation and management of large old trees. Biological Reviews, Cambridge, 000-000, 2016.

LINDENMAYER, D. B.; LAURANCE, W. F.; FRANKLIN, J. F. Global decline in large old trees. Science, Washington, vol. 338, p. 1305-1306, 2012.

LINDENMAYER, D. B. et al. New policies for old trees: averting a global crisis in a keystone ecological structure. Conserv. Lett., Oxford, v. 7, p. 61-69., 2013.

LUTZ, J. A. et al. Global importance of large-diameter trees. Global Ecol Biogeogr., Oxford, p.116, 2018.

MATTOS, J. R. O pinheiro brasileiro. Florianópolis: Editora da UFSC, 2011. p. 117-127.

PREFEITURA DE SÃO JOAQUIM. Monumento conta a História de São Joaquim. Disponível em: http://www.saojoaquim.sc.gov.br/cms/pagina/ver/codMapaItem/5158. Acesso em: 16 jul. 2018. 
PILLAR, V.D. Suficiência amostral. In: BICUDO, C.E.M.; BICUDO, D.C. Amostragem em limnologia. São Carlos: RIMA, 2004. p.25-43.

PREFEITURA DE TAPEJARA. Pinheiro. Disponível em: <http://www.tapejara.rs.gov.br/ turismo>. Acesso em: 15 jul. 2018.

REITZ, R.; KLEIN, R. M.; REIS, A. Projeto Madeira de Santa Catarina. Itajaí, SC: HBR; Porto Alegre: Sudesul, 1978. 320 p.

RIO GRANDE DO SUL. Inventário Florestal Contínuo do Rio Grande do Sul. Disponível em: http://coralx.ufsm.br/ifcrs/frame.htm. Acesso em: 26 set. 2018.

SANTA CATARINA (Estado). Lei no 17.308, de novembro de 2017. Consolida as Leis que dispõem sobre Símbolos Estaduais e Regionais do Estado de Santa Catarina. Disponível em: http://leis.alesc.sc.gov.br/html/2017/17308_2017_lei.html. Acesso em: 16 out. 2018.

SANTOS, A. J. dos et al. Aspectos Produtivos e Comerciais do Pinhão no Estado do Paraná. Floresta, Curitiba, v. 32, n. 2, p. 163-169, 2002.

SANTOS, A. T. dos et al. Determinação da Época de Desbaste pela Análise Dendrocronológica e Morfométrica de Ocotea porosa (Nees \& Mart.) Barroso em Povoamento Não Manejado. Ciência Florestal, Santa Maria, v. 25, n. 3, p. 699-709, jul.-set., 2015.

SCIPIONI, M. C. Araucárias Monumentais: um patrimônio em reconhecimento. In: III SEMINÁRIO SUL-BRASILEIRO SOBRE A SUSTENTABILIDADE DA ARAUCÁRIA, 2018, Passo Fundo. Anais... Passo Fundo: UPF, 2018. p.127-129.

SCIPIONI et al. The last giant Araucaria trees in southern Brazil. Scientia Agricola, Piracicaba, v.76, n.3, p. 220-226, mai.-jun., 2019.

STRONG, D. From Pioneers to Preservationists: a brief history of Sequoia and King Canyon National Parks. Three Rivers: Sequoia Natural History Association, 2000. 60 p.

THOMAS, P. Araucaria angustifolia. In: IUCN 2013. The IUCN Red List of Threatened Species. Disponível em: http://dx.doi.org/10.2305/IUCN.UK.2013-1.RLTS.T32975A2829141.en. Acesso em: 28 set. 2018.

TNG, D. Y. P et al. Giant eucalypts - globally unique fire-adapted rain-forest trees? New Phytologist, Oxford, v. 196, p. 1001-1014, 2012.

VAN PELT, R. Forest giants of the Pacific coast. Seattle: University of Washington Press, 2001. $200 \mathrm{p}$.

VARTY, N., GUADAGNIN, D.L. Ocotea porosa. In: IUCN 1998. The IUCN Red List of Threatened Species. Disponível em: http://dx.doi.org/10.2305/IUCN.UK.1998.RLTS.T32978A9739985.en. Acesso em: 28 set. 2018.

VIBRANS, A. C. et al. Inventário Florístico Florestal de Santa Catarina: Floresta Ombrófila Mista. Blumenau: Edifurb, vol. 3, 2013. 440 p. 